SABRAO Journal of Breeding and Genetics

53 (4) 609-619, 2021

http://doi.org/10.54910/sabrao2021.53.4.5

http://sabraojournal.org/

pISSN 1029-7073; eISSN 2224-8978

\title{
GENOTYPE BY ENVIRONMENT INTERACTION ANALYSIS OF WHEAT (Triticum aestivum L.) GRAIN YIELD UNDER RAIN-FED CONDITIONS IN ZAMBIA
}

\author{
B. TEMBO \\ Zambia Agricultural Research Institute (ZARI), Mt. Makulu Central Research Station, P/B 7, \\ Chilanga, Zambia \\ *Corresponding author email: batemfe@yahoo.com
}

\begin{abstract}
SUMMARY
Understanding genotype by environment interaction (GEI) is important for crop improvement because it aids in the recommendation of cultivars and the identification of appropriate production environments. The objective of this study was to determine the magnitude of GEI for the grain yield of wheat grown under rain-fed conditions in Zambia by using the additive main effects and multiplicative interaction (AMMI) model. The study was conducted in 2015/16 at Mutanda Research Station, Mt. Makulu Research Station and Golden Valley Agricultural Research Trust (GART) in Chibombo. During2016/17, the experiment was performed at Mpongwe, Mt. Makulu Research Station and GART Chibombo, Zambia. Fifty-five rain-fed wheat genotypes were evaluated for grain yield in a $5 \times 11$ alpha lattice design with two replications. Results revealed the presence of significant variation in yield across genotypes, environments, and GEI indicating the differential performance of genotypes across environments. The variance due to the effect of environments was higher than the variances due to genotypes and GEI. The variances ascribed to environments, genotypes, and GEI accounted for $45.79 \%, 12.96 \%$, and $22.56 \%$ of the total variation, respectively. These results indicated that in rain-fed wheat genotypes under study, grain yield was more controlled by the environment than by genetics. AMMI biplot analysis demonstrated that E2 was the main contributor to the GEI given that it was located farthest from the origin. Furthermore, E2 was unstable yet recorded the highest yield. Genotype G47 contributed highly to the GEI sum of squares considering that it was also located far from the origin. Genotypes G12 and G18 were relatively stable because they were situated close to the origin. Their position indicated that they had minimal interaction with the environment. Genotype 47 was the highest-yielding genotype but was unstable, whereas G34 was the lowest-yielding genotype and was unstable.
\end{abstract}

Keywords: Genotype-environment interaction, additive main effects and multiplicative interaction analysis, genetics, stability, Triticum aestivum L.

Key findings: Results revealed that grain yield variation in wheat genotypes was mainly caused by the environment. Furthermore, the higher variance of GEI than that of genotype signified the importance of studies on GEI to the identification of high-yielding and stable wheat genotypes. 


\section{INTRODUCTION}

In Zambia, wheat (Triticum aestivum L.) is the second most important cereal crop after maize. It is grown under two agroclimatic systems: rain-fed (wet, warm, and humid conditions, NovemberMarch) and irrigated systems (cool and dry conditions, May-September). Rain-fed wheat production is mostly undertaken by smallholder farmers because it is less expensive than irrigated production. Average wheat yields under rain-fed systems range from $1 \mathrm{tha}^{-1}$ to $2 \mathrm{t} \mathrm{ha}^{-1}$, whereas those under irrigated systems are $8.0 \mathrm{t} \mathrm{ha}^{-1}$. Rain-fed wheat yields are not only low, they also fluctuate considerably. Their fluctuation can be attributed to different stresses, such as heat, drought, rainfall, soils, and diseases, and/or lack of improved and adaptable varieties (Tembo, 2019). Yan and Kang (2003) reported that the performance of a genotype in an environment is a function of genotype, environment, and genotype by environment interaction (GEI). An understanding of the effects of the environment and its interaction with genotype could help identify environments that are suitable for certain genotypes (Annicchiarico, 1992). Thus, the assessment of genotypes across varying environments might be essential for selecting genotypes with high mean yields for wide or specific adaptation to improve the productivity of rain-fed wheat in Zambia. Tadesse et al. (2018) reported that a cultivar with a high mean yield and low degree of fluctuation when grown in diverse environments is desirable. Until now, no work has been carried out to study the effect of GEI on grain yield under rain-fed systems in Zambia.

GEI is the differential expression of genotypes in response to changing environmental conditions (Sabaghnia et al., 2013). The differential expression of genotypes under changing environmental conditions is of great concern to plant breeders (Elakhdar et al., 2017) because it reduces relationships between phenotypic and genotypic values, thereby decelerating genetic progress (İlker et al., 2009). Moreover, it increases the cost of testing because it requires evaluating genotypes in several environments (location and years) to obtain dependable results (Kang, 1998).

GEI can either be noncrossover or crossover. Noncrossover GEI is said to occur when one genotype outperforms other genotypes across all test environments (Hongyu et al., 2014). In noncrossover interaction, the ranking of genotypes remains constant across test environments. Crossover interaction occurs when genotypes exhibit differential and inconsistent responses to test environments (Annicchiarico, 1992). In crossover interaction, no genotype is superior in a number of environments and the ranking of genotypes changes from one environment to another (Gauch, 2013). Ding et al. (2008) and Farshadfar et al. (2012) reported that the crossover type of interaction complicates the selection of superior genotypes and hence makes recommending varieties difficult due to the varying composition of the selected genotypes in different environments. Annicchiarico (1992) considered crossover interaction as a limitation to crop improvement. Nonetheless, an understanding of the scale and nature of GEI is crucial for designing suitable breeding tactics. With the change in environmental conditions, GEI effects must not be overlooked but instead should be exploited.

Plant breeders use numerous methods to exploit GEI and identify superior genotypes for either specific (crossover type) or wide adaptation (noncrossover) (Gauch et al., 2008; Kang, 2020). Among such methods is the additive main effects and multiplicative 
Table 1. Weather data of the six sites used in the study during 2015-16 and 2016-17 seasons.

\begin{tabular}{clccccccc}
\hline $\begin{array}{c}\text { Environ- } \\
\text { ments } \\
\text { (E) }\end{array}$ & Location & Season & Latitude & Longitude & Altitude & Rainfall & \multicolumn{2}{c}{ Memperature ${ }^{\circ} \mathrm{C}$} \\
\hline E1 & Mtanda & $2015 / 16$ & $12^{\circ} 25.95^{\prime} \mathrm{S}$ & $26^{\circ} 12.62^{\prime} \mathrm{E}$ & $1300.0 \mathrm{~m}$ & 941.9 & 28.4 & Min \\
E2 & Mt. Makulu & $2015 / 16$ & $15^{\circ} 32.9466^{\prime} \mathrm{S}$ & $28^{\circ} 15.078^{\prime} \mathrm{E}$ & $1224.0 \mathrm{~m}$ & 868.8 & 28.7 & 17.5 \\
E3 & GART & $2015 / 16$ & $14^{\circ} 58.185^{\prime} \mathrm{S}$ & $28^{\circ} 06.134^{\prime} \mathrm{E}$ & $1148.0 \mathrm{~m}$ & 695.8 & 27.8 & 17.9 \\
E4 & Mpongwe & $2016 / 17$ & $12^{\circ} 06.622^{\prime} \mathrm{S}$ & $31^{\circ} 14.660^{\prime} \mathrm{E}$ & $1220.1 \mathrm{~m}$ & 1216.1 & 28.8 & 15.6 \\
E5 & Mt. Makulu & $2016 / 17$ & $13^{\circ} 32.831^{\prime} \mathrm{S}$ & $28^{\circ} 03.626^{\prime} \mathrm{E}$ & $1225.0 \mathrm{~m}$ & 931.2 & 29.1 & 16.6 \\
E6 & GART & $2016 / 17$ & $1^{\circ} 58.0566^{\circ} \mathrm{S}$ & $28^{\circ} 05.875^{\prime} \mathrm{E}$ & $1147.0 \mathrm{~m}$ & 756.8 & 27.2 & 17.4 \\
\hline
\end{tabular}

interaction (AMMI) model. AMMI is among the most widely used statistical method for studying and interpreting GEI (Hongyu et al., 2014). It is considered to be an effective tool for detecting GEI because it has few degrees of freedom and describes interaction in more than one dimension (Vargas et al., 2001). Another essential element of AMMI is that it integrates analysis of variance (ANOVA, an additive model) for the effect of genotype and environment with principal component analysis (PCA, a multiplicative model) for GEI into a single analysis (Kandus et al., 2010). Furthermore, AMMI captures a massive portion of GEI and separates the main and interaction effects (Gauch, 2013; Elakhdar et al., 2017). Another attractive component of AMMI analysis is its biplots. AMMI biplots are used to visualize the performance of genotypes in each environment and to visualize and understand GEIs. Biplots form the patterns and associations of genotypes and environments (Mohammadi et al., 2018).

In view of the above information, this study aimed i) to determine the magnitude of GEI on the grain yield of wheat genotypes under rain-fed conditions by using the AMMI model; ii) to identify the best yielding and stable genotypes across test environments; and iii) to investigate the relationship among test environments for evaluating rain-fed wheat genotypes in Zambia.

\section{MATERIALS AND METHODS}

The experiment was conducted for two consecutive cropping seasons during 2015/16 and 2016/17 at three sites in Zambia. In the 2015/16 season, the study was carried out at Mtanda Research Station (located at $12^{\circ} 25.959 ' S$ and $26^{\circ} 12.620^{\prime} \mathrm{E}$, Environment 1), Mt. Makulu Research Station (15 32.946 'S and $28^{\circ} 15.078^{\prime} \mathrm{E}$, Environment 2), and Golden Valley Agricultural Research Trust (GART) (14 ${ }^{\circ} 58.185^{\prime} S$ and $28^{\circ} 06.134^{\prime} \mathrm{E}$, Environment 3) in Chibombo district. The experiment during the 2016/17 season was performed at Mpongwe Seed-Co Research Farm located at $12^{\circ} 06.622$ 'S and 31 $14.660^{\prime} E$ (Environment 4), Mt. Makulu Research Station at $13^{\circ} 32.831^{\prime} S$ and $28^{\circ} 03.626^{\prime} \mathrm{E}$ (Environment 5), and GART (14 ${ }^{\circ} 58.056^{\prime} S$ and $28^{\circ} 05.875^{\prime} \mathrm{E}$, Environment 6 ). The mean temperatures and average annual rainfall of the locations and seasons are presented in Table 1.

A total of 55 elite wheat genotypes were used in this study. The genotypes were obtained from Zambia Agriculture Research Institute (ZARI), Chilanga, Zambia, and the International Maize and Wheat Improvement Center (CIMMYT), ElBatan, Mexico. The experiment was laid out in a $5 \times 11$ alpha lattice design with two replications in all locations and seasons. Each genotype was planted in four rows of $3 \mathrm{~m}$ long with $20 \mathrm{~cm}$ interrow spacings. The spacing between 
plots was $40 \mathrm{~cm}$. At planting, Compound D (10\% N: $20 \% \mathrm{P}: 10 \% \mathrm{~K}$ ), a basal dressing fertilizer, was applied at the rate of $300 \mathrm{~kg}$ $\mathrm{ha}^{-1}$. At the first node stage, urea ( $46 \%$ $\mathrm{N})$ was applied as the top dressing to all plots at the rate of $150 \mathrm{~kg} \mathrm{ha}^{-1}$. All plots were harvested at maturity.

\section{Statistical analyses}

The collected data were subjected to ANOVA by using restricted or residual maximum likelihood in Genstat, version 18 (VSN International, 2015) to investigate the apportioning of the sum of squares to genotype, environment, and GEI. Genotypes, locations, years, and their interactions were considered fixed, whereas replications and blocks were considered as random effects.

AMMI analysis was conducted by using the following model equation (Gauch, 2013):

$$
Y_{i j}=\mu+a_{i}+\beta_{j}+\Sigma_{n} \lambda_{n}+Y_{i n}+\delta_{j n}+\rho_{i j}
$$

where $Y i j$ is the yield of the $i$-th genotype in the $j$-th environment; $\mu$ is the grand mean; $a_{i}$ is the genotype deviation from the grand mean; $\beta_{j}$ is the environment deviation; $\lambda_{n}$ is the square root of the eigenvalue of the interaction principal component axis (PCA) $n ; Y_{\text {in }}$ is the eigenvector value for genotype $i$ and component $n ; \delta_{j n}$ is the eigenvector value for environment $j$ and component $n$, with both eigen vectors scaled as unit vectors; and $\rho_{\mathrm{ij}}$ is the residual term. AMMI analysis was conducted in Genstat, version 18 (VSN International, 2015). AMMI biplots were used to visualize the performance of genotypes in each environment; to visualize and understand GEI; and to explore relationships among the test environments in their ranking of genotypes in terms of yield. Angles of $<90^{\circ}$ between test environments indicate positive correlations, whereas right angles show no correlation. Test environments with angles $>90^{\circ}$ indicate negative correlations (Yan and Tinker, 2006).

\section{RESULTS}

\section{Combined ANOVA}

The combined analysis of variance of the Wald test statistics showed that all the components of variance, genotypes, environments, and GEI were highly significant $(P \leq 0.001)$ for grain yield (Table 2). The GEI components, genotype $\times$ location, genotype $\times$ year, and genotype $\times$ year $x$ location effects were also highly significant $(P<0.001)$. ANOVA results suggested the need for conducting AMMI analysis to further split the GEI effects into different interaction components as indicated by Mujahid et al. (2011) and Hongyu et al. (2014).

Table 2. Combined analysis of variance (Wald tests for fixed effects) for wheat grain yield across six locations during 2015-16 and 2016-17 seasons.

\begin{tabular}{llccc}
\hline \multicolumn{2}{l}{ Sequentially added terms to the fixed model } & & & \\
\hline Fixed term & Wald statistic & d.f. & Wald/d.f. & chi pr \\
\hline Genotype (G) & 206.08 & 54 & 3.82 & $<0.001$ \\
Location (L) & 552.72 & 2 & 276.36 & $<0.001$ \\
Year (Y) & 236.34 & 1 & 236.34 & $<0.001$ \\
G $\times$ L & 185.75 & 108 & 1.72 & $<0.001$ \\
G $\times$ Y & 103.22 & 54 & 1.91 & $<0.001$ \\
Y $\times$ L & 164.96 & 2 & 82.48 & $<0.001$ \\
G $\times$ Y $\times$ L & 137.77 & 108 & 1.28 & 0.028 \\
\hline
\end{tabular}

d.f. $=$ degree of freedom, chi $\mathrm{pr}=$ chi probability 
Table 3. ANOVA of the AMMI model for the grain yields of the genotypes evaluated across six locations during $2015-16$ and $2016-17$ seasons.

\begin{tabular}{|c|c|c|c|c|c|c|}
\hline Source & d.f. & $\begin{array}{l}\text { Sum of } \\
\text { squares (SS) }\end{array}$ & $\begin{array}{l}\text { Mean square } \\
\text { (MS) }\end{array}$ & SS (\%) & $\begin{array}{c}\text { Treatment } \\
\text { TSS (\%) }\end{array}$ & $\begin{array}{c}G \times \underset{E}{\mathrm{E}-\mathrm{SS}} \\
(\%)\end{array}$ \\
\hline Treatments & 329 & 1083374 & $3293 * * *$ & 81.31 & & \\
\hline Genotypes (G) & 54 & 172639 & $3197 * * *$ & & 15.94 & \\
\hline Environments & 5 & 610113 & $122023 * * *$ & & 56.32 & \\
\hline Block & 6 & 2705 & $451^{\mathrm{ns}}$ & & & \\
\hline $\begin{array}{l}\text { Interactions } \\
\text { (GEI) }\end{array}$ & 270 & 300622 & $1113 * * *$ & & 27.75 & \\
\hline IPCA1 & 58 & 170858 & $2946 * * *$ & & & 56.83 \\
\hline IPCA2 & 56 & 59993 & $1071 * *$ & & & 19.96 \\
\hline Residuals & 156 & 69771 & $447^{\text {ns }}$ & & & 23.21 \\
\hline Error & 324 & 246270 & 760 & 18.48 & & \\
\hline Total & 659 & 1332349 & 2022 & & & \\
\hline
\end{tabular}

\section{Performance of genotypes across environments}

The yields of genotypes across environments and years ranged between 0.28 and $3.65 \mathrm{t} \mathrm{ha}^{-1}$. The best-yielding genotype across environments was G47 with the mean yield of $3.65 \mathrm{t}$ ha ${ }^{-1}$, followed by genotype $\mathrm{G} 44$ with the yield of $3.41 \mathrm{t} \mathrm{ha}^{-1}$. Genotype $\mathrm{G} 34$ provided the lowest mean yields $\left(0.28 \mathrm{t} \mathrm{ha}^{-1}\right)$ across environments. During the 2015/2016 season, the highest yield was observed in environment E2, and the best yielder was genotype G47 with the yield of $6.94 \mathrm{t}$ $\mathrm{ha}^{-1}$. In E1, G53 (2.65 $\mathrm{t} \mathrm{ha}^{-1}$ ) was the highest yielder, whereas in E3 the topyielding genotype was G54 with the yield of $4.21 \mathrm{t} \mathrm{ha}^{-1}$. During the 2016/2017 season, the highest-yielding genotypes in $\mathrm{E} 4, \mathrm{E} 5$, and E6 were G51 (3.33 $\mathrm{t} \mathrm{ha}^{-1}$ ), G39 (5.72 t ha ${ }^{-1}$ ), and G26 (4.09 t ha ${ }^{-1}$ ), respectively. These results indicated the probable existence of GEI effects as environments and seasons had different top-yielding genotypes.

\section{AMMI ANOVA}

The ANOVA of the AMMI model showed that the environment, genotypes, and GEI were highly significant at $P<0.001$ (Table $3)$. The environment, genotype, and GEI explained $45.79 \%, 12.96 \%$, and $22.56 \%$ of the total sum of squares, respectively. The environmental effect was approximately three times larger than the genotypic effect and twice the GEI. The total explained treatment sum of squares was $81.31 \%$. The genotypes, environments, and GEI effects accounted for $15.94 \%, 54.32 \%$, and $27.75 \%$ of the treatment variation, respectively. The combination of the genotypic and GEI components accounted for $46.69 \%$ of the treatment variation.

The GEI components, interaction PCA 1 (IPCA 1), and IPCA 2 were highly significant $(P<.0001)$. IPCA 1 explained $56.83 \%$ of the total GEI, and IPCA 2 explained $19.96 \%$ of the total GEI. The two principal components together explained $76.79 \%$ of GEI.

\section{AMMI biplot analysis of genotypes and environments for grain yield}

The AMMI biplot showed that genotypes G12 and G18 were closer to the origin and had an IPCA 1 score that was close to zero (Figure 1). Genotypes G34, G43, G16, and G54 had positive IPCA 1 scores but were located far from the origin, whereas G47 and G44 had negative IPCA 1 scores and were far away from the origin. The highest-yielding genotype across environments was G47, followed by G44, and G34 was the lowest-yielding genotype (Table 4, Figure 1). E1, E3, E4, and E6 had positive IPCA 1 values, whereas E5 and E2 had negative IPCA 1 values. E5 was slightly closer to the origin than the 
other environments, whereas E2 was far from the origin and had a large negative IPCA 1 value. E2 interacted strongly with genotypes with the same IPCA 1 sign, such as G47. E2 recorded the highest mean yield, followed by E6, then E5, whereas E1 had the lowest yield (Table 5, Figure 1).

Figure 2 of the AMMI biplot was used to explore GEI, discriminating ability, and the relationship of the test environments. E2 and E5 had negative PC1 scores, whereas the remaining environments in the study had positive
PC1 scores (Figure 2). E2 was located far from the origin. E5 had negative PC2 scores, and the other environments had positive PC2 scores. The PC2 score of E6 was close to the origin, followed by that of E4. E2 had the longest vector, followed by $E 5$, then by E1, E3, and E4. E6 had the shortest vector. Furthermore, the angle between E2 and the other environments was very large $\left(>90^{\circ}\right)$. The angle between $\mathrm{E} 5$ and $\mathrm{E} 1, \mathrm{E} 3$, and $\mathrm{E} 4$ was also large $\left(>90^{\circ}\right)$. The smallest angle was observed among environments E1, E3, E4, and E6 $\left(<90^{\circ}\right)$.

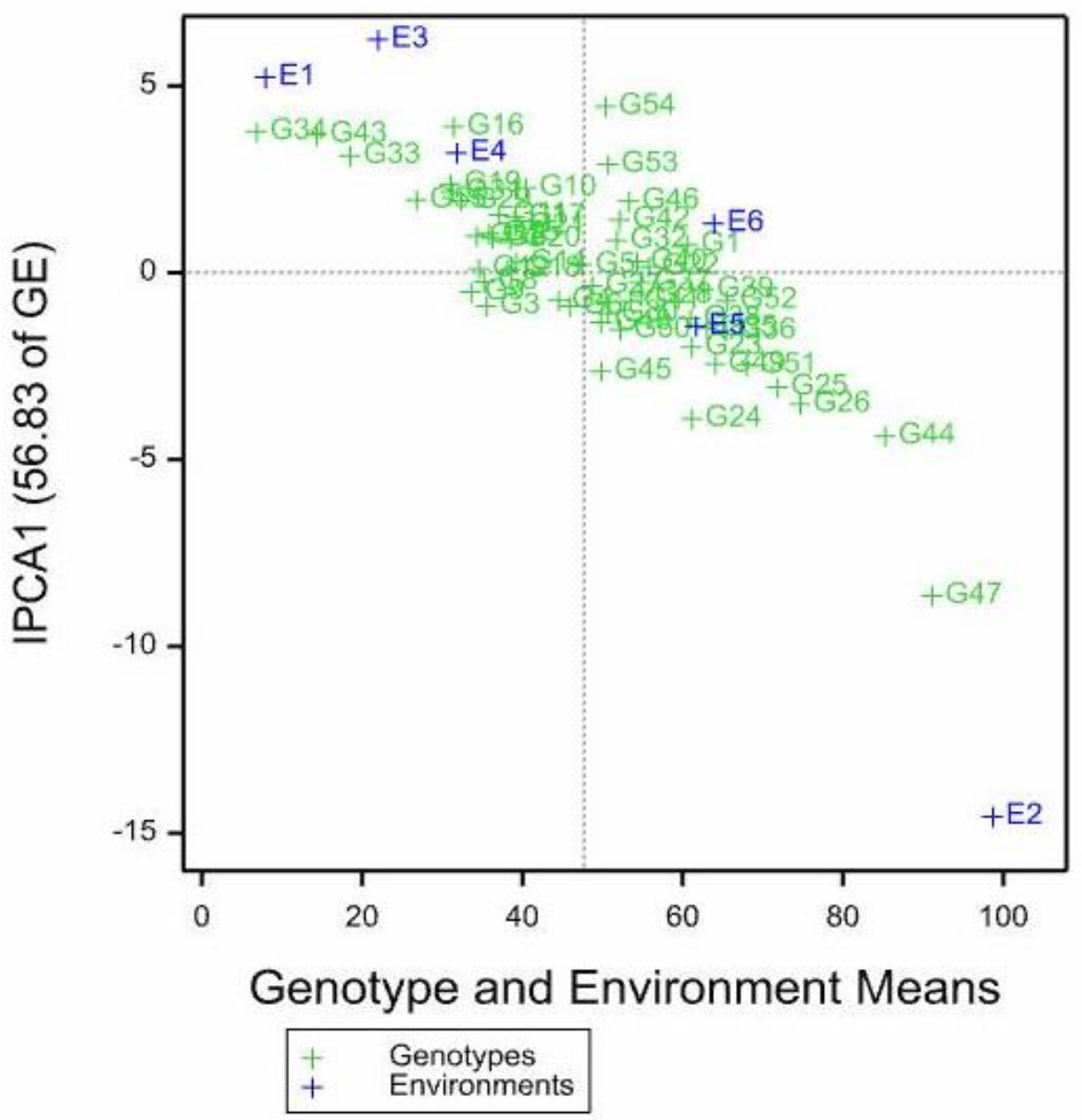

Figure 1. AMMI biplot displaying the mean performance of wheat genotypes and environments for grain yield under rain-fed conditions. Note: The names of the environments are given in Table 1. 
Table 4. Average grain yields of 55 rain-fed wheat genotypes evaluated across six test environments during 2015-16 and 2016-17 seasons.

\begin{tabular}{clllll}
\hline $\begin{array}{c}\text { Genotype } \\
\text { code }\end{array}$ & $\begin{array}{l}\text { IPCA 1 } \\
\text { score }\end{array}$ & $\begin{array}{l}\text { Grain yield } \\
\left(\mathrm{kg} \mathrm{ha}^{-1}\right)\end{array}$ & $\begin{array}{c}\text { Genotype } \\
\text { code }\end{array}$ & $\begin{array}{l}\text { IPCA 1 } \\
\text { score }\end{array}$ & $\begin{array}{l}\text { Grain yield } \\
\left(\mathrm{kg} \mathrm{ha}^{-1}\right)\end{array}$ \\
\hline G1 & 0.75212 & 2426.4 & $\mathrm{G} 29$ & 1.92889 & 1294.8 \\
G2 & 0.92613 & 1452.0 & $\mathrm{G} 30$ & -1.08906 & 2028.0 \\
G3 & -0.89608 & 1422.4 & $\mathrm{G} 31$ & 2.16022 & 1250.4 \\
G4 & -0.74449 & 1781.6 & $\mathrm{G} 32$ & 0.86385 & 2072.0 \\
G5 & 0.2066 & 1898.8 & $\mathrm{G} 33$ & 3.13147 & 741.6 \\
G6 & -0.8969 & 1835.2 & $\mathrm{G} 34$ & 3.77643 & 275.2 \\
G7 & 1.04724 & 1435.6 & $\mathrm{G} 35$ & -1.48398 & 2521.6 \\
G8 & -0.24323 & 1412.0 & $\mathrm{G} 36$ & -1.56199 & 2615.2 \\
G9 & -0.51845 & 1345.6 & $\mathrm{G} 37$ & -0.26804 & 2190.4 \\
G10 & 2.27024 & 1619.6 & $\mathrm{G} 38$ & -1.22498 & 2440.0 \\
G11 & 1.54824 & 1484.4 & $\mathrm{G} 39$ & -0.45528 & 2505.2 \\
G12 & 0.10404 & 1385.6 & $\mathrm{G} 40$ & 0.29589 & 2173.2 \\
G13 & 0.98086 & 1371.2 & $\mathrm{G} 41$ & -0.76246 & 2140.0 \\
G14 & 0.27014 & 1571.2 & $\mathrm{G} 42$ & 1.41394 & 2085.2 \\
G15 & 1.04734 & 1434.4 & $\mathrm{G} 43$ & 3.69077 & 574.8 \\
G16 & 3.9042 & 1258.4 & $\mathrm{G} 44$ & -4.37247 & 3411.6 \\
G17 & 1.50164 & 1565.2 & $\mathrm{G} 45$ & -2.64297 & 1994.8 \\
G18 & 0.09448 & 1542.8 & $\mathrm{G} 46$ & 1.91413 & 2132.8 \\
G19 & 2.36951 & 1243.6 & $\mathrm{G} 47$ & -8.64945 & 3645.6 \\
G20 & 0.89884 & 1541.6 & G48 & -1.32773 & 1993.6 \\
G21 & 1.24856 & 1565.2 & G49 & -2.4501 & 2562.8 \\
G22 & 0.15903 & 2231.6 & G50 & -1.52589 & 2089.6 \\
G23 & -1.98686 & 2445.6 & G51 & -2.48352 & 2720.4 \\
G24 & -3.91068 & 2447.2 & G52 & -0.75216 & 2620.0 \\
G25 & -3.06732 & 2874.8 & G53 & 2.89683 & 2028.8 \\
G26 & -3.52405 & 2986.8 & G54 & 4.44674 & 2015.6 \\
G27 & -0.35012 & 1948.4 & G55 & 1.94706 & 1072.4 \\
G28 & -0.60715 & 2196.4 & & & 1907.62 \\
\hline & & & &
\end{tabular}

Table 5. Average grain yield recorded per environment during 2015-16 and 2016-17 seasons.

\begin{tabular}{ccc}
\hline Environment code & IPCA 1 score & Grain yield $\left(\mathrm{kg} \mathrm{ha}^{-1}\right)$ \\
\hline E1 & 5.23015 & 319.2 \\
E2 & -14.5588 & 3948.4 \\
E3 & 6.23766 & 881.6 \\
E4 & 3.20495 & 1274 \\
E6 & -1.43208 & 2466.4 \\
\hline
\end{tabular}




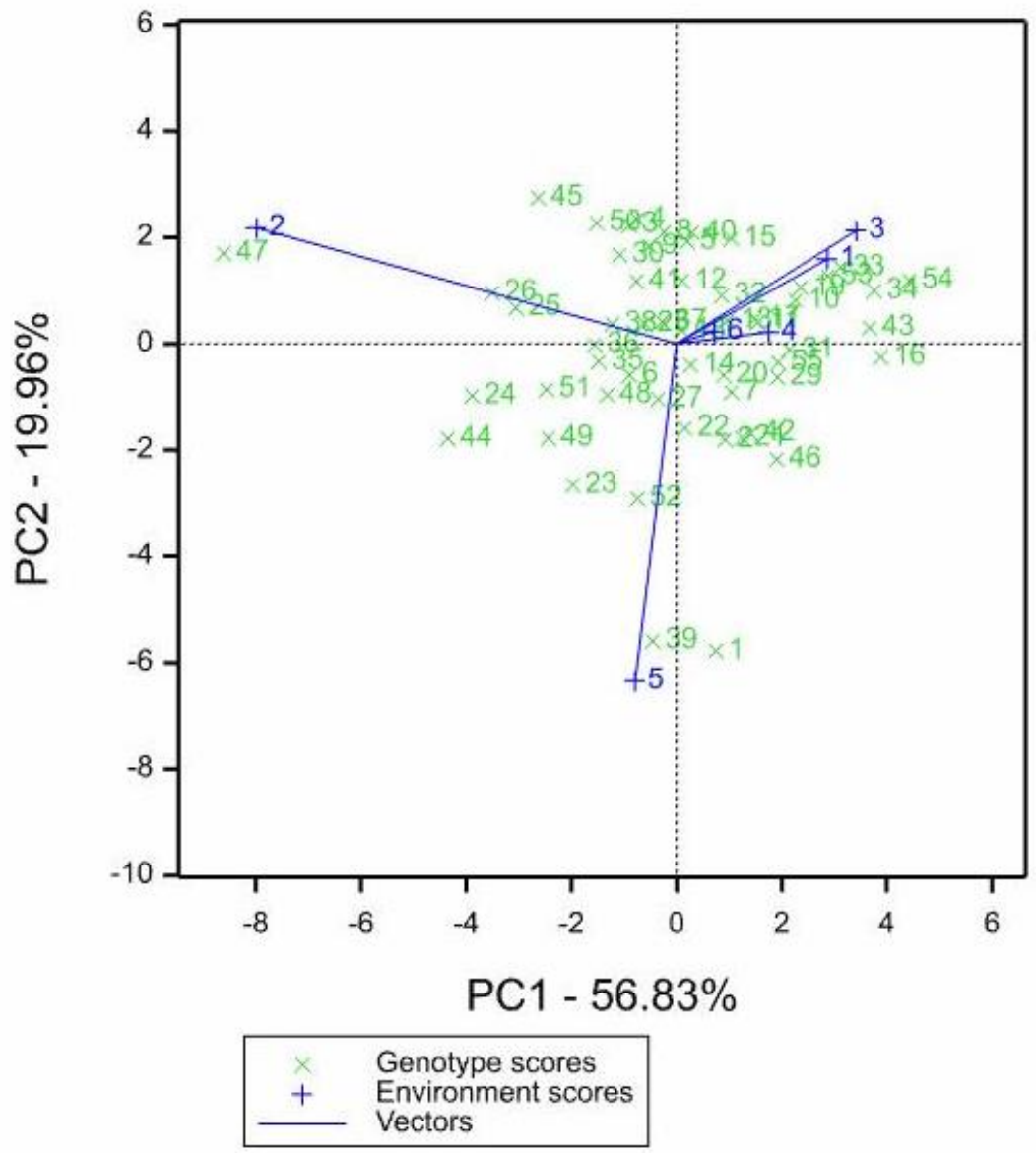

Figure 2. GEI biplot showing the relationship among test environments in discriminating wheat genotypes for grain yield under rain-fed conditions.

\section{DISCUSSION}

The significant differences observed in yield showed that the genotypes used in this study were genetically diverse in terms of grain yield and that the environments were also different. In this study, not one genotype showed consistent grain yield in more than one environment, indicating that the genotypes exhibited a crossover type of interaction. The crossover type of interaction is critical to plant breeders as it hampers progress in selection. Furthermore, it increases the cost of genotype evaluation because it necessitates assessment in numerous environments to achieve good results (Kang, 1988).

The high magnitude of sum of squares due to the environment indicated that the test environments were different and were the major contributors to the total variation in grain yield. This result showed that in rain-fed wheat under study, grain yield was more controlled by the environment than by genetics. The present results were similar to the past findings on the grain yield of wheat genotypes under rain-fed conditions (Kota et al., 2013; Motamedi et al., 2013; Nowosad et al., 2018). The larger GEI component than genotypic main effect indicated the occurrence of a remarkable GEI. 
Given that the variance of GEI was higher than that of genotype, the genetic improvement of grain yield in rain-fed wheat genotypes by selection could be less effective. The further testing of selected lines in several environments can be valuable for identifying high-yielding and stable genotypes.

The biplot of the IPCA 1 scores revealed that $\mathrm{G} 12$ and $\mathrm{G} 18$ were relatively stable and hence can be suitable for general adaptation (Figure 1). The very close location of these genotypes to the origin was an indication that they had limited interaction with the environment. Muhe and Assefa (2011) reported that IPCA 1 scores are indexes of the stability of a genotype across environments. They further pointed out that genotypes or environments with IPCA 1 scores closer to the origin are more stable than those with scores located away from the origin (either with positive or negative IPCA 1 scores). Genotypes G34, G43, G16, and G54 with positive IPCA 1 scores were unstable because they were located far from the origin. Genotype G34 was not only unstable but also very low yielding and thus cannot be selected for any environment. Furthermore, genotypes G47 and G44, which had negative IPCA 1 scores that were located very far from the origin, were very unstable. However, they were high yielding and hence are suitable for specific adaptation.

E5 and E6 were moderately stable because they were located close to the origin and had Iow IPCA1 scores (Figure 1). Furthermore, E5 and E6 had moderately high yields. Environments with positive IPCA 1 scores but were located far from the origin, such as $E 1$, were unstable and low yielding. E2 was high yielding but very unstable. The high yields observed in E2 could be due to the favorable temperatures and good rains in this location (Table 2). E2 was the most discriminating environment of genotypes for grain yield because it had the longest vector, followed by E5, then by E1, E3, and E4. E6, which had the shortest vector, was the least-discriminating genotype for grain yield and was hence less informative than other genotypes. Badu-Apraku et al. (2013) reported that environments with long vectors had the greatest discriminating ability, indicating that the genotypic variations observed in these environments could be dependable for the selection of genotypes. The environments could be ranked in terms of the discriminating ability of the genotypes for grain yield as follows: E2 > E5 > E1 > E3 $>\mathrm{E} 4>\mathrm{E} 6$.

The smallest angles $\left(<90^{\circ}\right)$ were observed among E1, E3, E4, and E6 (Figure 2), indicating that these environments had a positive relationship. This implies that these environments produced comparable information regarding the genotypes. Thus, one of these environments could be used for evaluating genotypes without losing any information about the genotypes. By contrast, a negative relationship was observed between E2 and the rest of the environments and between E5 and the other environments. This observation was based on the principle that test environments are positively associated when the angle between them is less than $90^{\circ}$ and are negatively related when the angle between them is $>90^{\circ}$ (Ali et al., 2015).

The biplot in Figure 2 revealed that E2 had the greatest contribution to the GEI sum of squares as shown by its distance to the origin. E4 and E6 had low contributions to the GEI sum of squares as indicated by their close location to the origin. By contrast, G47 was the major contributor to the GEI considering that it was farthest from the origin. Genotypes or environments close to the origin have a smaller interaction effect than those far from the origin (Ali et al., 2015). Genotype 47 was specifically adapted to E2, and G39 and G1 were specifically adapted to E5. 


\section{CONCLUSIONS}

The results revealed that the environment was the major contributor to the total variation in the grain yield of the rain-fed wheat genotypes under study, hence signifying the importance of conducting GEI analysis in Zambia. AMMI revealed that genotypes $\mathrm{G} 12$ and $\mathrm{G} 18$ were close to ideal genotypes and had low interaction with the environment. This result implied that these genotypes had almost stable yields across environments and thus could be used as source materials for breeding or as varieties for broadened adaption. Genotype 47 was high yielding, unstable, and specifically adapted to E2. Furthermore, E5 and E6 were identified as moderately stable environments with moderate interaction effect, and E2 was identified as unstable but high yielding. G47 and E2 were found to be the main contributors to GEI effects.

\section{REFERENCES}

Ali MD, El-Sadek AN, Sayed MA, Hassaan MA (2015). AMMI biplot analysis of genotype $\times$ environment interaction in wheat in Egypt. J. Plant Breed. 19(6): 1889-1901.

Annicchiarico P (2002). Genotype $\times$ environment interactions - Challenges and opportunities for plant breeding and cultivar recommendations.

Badu-Apraku B, Akinwale RO, Obeng-Antwi K, Haruna A, Kanton R, Usman IS, Ado G, Coulibaly N, Yallou GC, Oyekunle M (2013). Assessing the representativeness and repeatability of testing sites for drought-tolerant maize in West Africa. Can. J. Plant Sci. 93(4): 699-714.

Ding M, Tier B, Yan W (2008). Application of GGE biplot analysis to evaluate genotype (G), environment (E) and $G$ $\times \mathrm{E}$ interaction on $P$. radiata: $A$ case study. New Zealand J. For. Sci. 38(1): 132-142.

Elakhdar A, Kumamaru T, Smith KP, Brueggeman RS, Capo-chichi LJA, Shyam Solanki S (2017). Genotype by environment interactions (GEIs) for barley grain yield under salt stress condition. J. Crop Sci. Biotechnol. 20(3): 193- 204.

Farshadfar E, Mohammadi R, Aghaee M, Vaisi Z (2012). GGE biplot analysis of genotype $x$ environment interaction in wheat-barley disomic addition lines. Aust. J. Crop Sci. 6(6): 1074-1079.

Gauch HG Jr (2013). A simple protocol for AMMI analysis of yield trials. Crop Sci. 53: 1860-1869.

Gauch HG Jr, Piepho H, Annicchiarico P (2008). Statistical analysis of yield trials by AMMI and GGE: further considerations. Crop Sci. 48: 866-889.

Hongyu K, Garcia-Pena M, de Araujo LB, Dias CTS (2014). Statistical analysis of yield trials by AMMI analysis of genotype $x$ environment interaction. Biomet. Letters 51(2): 89-102.

İlker E, Tonk FA, Çaylak Ö, Tosun M, Özmen, İ (2009). Assessment of genotype $x$ environment interactions for grain yield in maize hybrids using AMMI and GGE biplot analyses. Turk. J. Field Crops 14(2): 123 - 135.

Kandus M, Almorza D, Boggio R, Salerno JC (2010). Statistical models for evaluating the genotype - environment interaction in maize (Zea mays L.). Int. J. Exp. Bot. 79: 39-46.

Kang M (2020). Genotype - environment interaction and stability analyses: An update. CABI International.

Kang MS (1998). Using genotype-byenvironment interaction for crop cultivar development. Adv. in Agron. 62: 199-252.

Kota S, Singh SS, Mohapatra T, Singh AM, Brajendra, AM, Bhadana, VP, Ravichandran S (2013). Genotype $\times$ environment interaction analysis for grain yield in new plant type (NPT) wheat derivatives. SABRAO J. Breed. Genet. 45(3): 382-390.

Mohammadi R, Armion M, Zadhasan E, Ahmadi MM, Amri A (2018). The use of AMMI model for interpreting genotype $x$ environment interaction in durum wheat. Exp. Agric. 54(5): 670-683.

Motamedi M, Safari P, Mohammadi G (2013). Additive main effect and multiplication interaction analysis of grain yield in bread wheat genotypes across environments. Int. J. Biosci. 3(8): 218225.

Muhe K, Assefa A (2011). Genotypes × environment interaction in bread wheat (Triticum aestivum L.) cultivar 
development in Ethiopia. Int. Res. J. Plant Sci. 2(10): 317-322.

Mujahid MY, Ahmad Z, Ashraf M, Khan MN, Asif M, Qamar M (2011). GGE biplot analysis of advanced bread wheat lines across different sites of Pakistan. Pak. J. Bot. 43(1): 293-299.

Nowosad K, Tratwal A, Bocianowski J (2018). Genotype by environment interaction for grain yield in spring barley using additive main effects and multiplicative interaction model. Cereal Res. Commun. 46(4): 729-738.

Sabaghnia N, Karimizadeh R, Mohammadi M (2013). GGL biplot analysis of durum wheat (Triticum turgidum spp. durum) yield in multi-environment trials. Bulgarian J. Agric. Sci. 19 (4): 756765.

SAS Institute Inc. (2011). SAS 9.3 Software: Cary, NC: SAS Institute Inc.

Tadesse T, Sefera G, Tekalign A (2018). Genotypes $\times$ environment interaction analysis for Ethiopian mustard
(Brassica carinata L.) genotypes using AMMI model. J. Plant Breed. Crop Sci. 10: $86-92$

Tembo B (2019). A review of rain-fed wheat production constraints in Zambia. J. Agric. and Crops 5: 158-161.

Vargas M, Crossa J, van Eeuwijk F, Sayre KD, Reynolds MP (2001). Interpreting treatment environment interaction in agronomy trials. Agron. J. 93: 949960.

VSN International (2015). Genstat for windows $18^{\text {th }}$ Edition. VSN International, Hemel Hempstead, UK. Web page: Genstat.Co.UK.

Yan W, Kang MS (2003). GGE biplot Analysis: A graphical tool for breeders, geneticists, and agronomists. CRC Press, Boca Raton, FL. ISBN 9780367454791.

Yan W, Tinker NA (2006). Biplot analysis of multi-environment trial data: Principles and applications. Can. J. Plant Sci. 86: 623-645. 